\title{
PERFECTIONISM AT YOUNGER ADOLESCENTS: ASSOCIA- TIONS WITH DIFFERENT ASPECTS OF ANXIETY
}

\section{Vesna Ćorluka Čerkez ${ }^{1}$ Tamara Efendić-Spahić}

Teaching faculty, University „Džemal Bijedic'“ of Mostar

Faculty of Philosophy, University of Tuzla
UDC: 159.922 .8

$37.048: 17.036 .2$

$159.94-053.6$

\begin{abstract}
Although it has been determined that childhood and adolescence are the most important periods for the development of perfectionism, there are few empirical data on perfectionism in general, as well as on its relation to anxiety, available for this population. Due to that, the goal of our research was to question the relation between perfectionism and anxiety among younger adolescents. The research has been conducted among students of two elementary schools in Mostar $(N=200)$. The following instruments were applied: Questionnaire on socio-demographic features, Adaptive/maladaptive perfectionism scale (Rice \& Preusser, 2002); Children and adolescents perfectionism scale (Flett, Hewitt, Boucher, Davidson \& Munro, 2000) and Fears and anxiety scale for children and adolescents - SCAD-62 (Vulić-Prtorić, 2004). Based on the relation between perfectionism and anxiety measures and its contribution to explanation of anxiety, the following dimensions turned out to be maladaptive: sensitivity to mistakes, need for admiration, organisation and order and socially prescribed perfectionism. Contingent self-esteem and self-oriented perfectionism stand out as adaptive.
\end{abstract}

Key words: perfectionism, anxiety, adolescents

\section{INTRODUCTION}

In general, perfectionism could be observed as an aspiration to perfection that can affect psychological well-being of a person, both positively and negatively. The effect of perfectionism on the development of anxiety, depression and emotional difficulties was first discussed by the Stoics and Epictetus (1899, according to Flett \& Hewitt, 2002), Pierre Janet (1898, according to Flett \& Hewitt, 2002), Alfred Adler (1926; 1927, Schuler, 1999; according to Hadžić, 2011) and Karen Horney (1950, according to Shafran \& Mansell, 2001), in their personality theories. Karen Horney (1950, according to Shafran \& Mansell, 2001) describes perfectionism as a ,tyranny of needing“, since perfectionists most often think about everything they need to do, achieve or accomplish in a perfect way. According to the same authors, Horney believed that excessive need for perfection is a usual reaction of persons who have poor opinion of themselves. Actually, she claimed that perfectionism is a neurotic aspiration and that perfectionists can perceive the most innocent negative feedback as a complete failure (Horney, 1950, according to Shafran \& Mansell, 2001). Contrary to that, Adler (1956, according to Flett \& Hewitt, 2002) believed that an aspiration to perfection is positive and it represents an essential part in human reaction to the feeling of inferiority and inefficiency. He differed (1956, according to Rice \& Preusser, 2002) adaptive and maladaptive perfectionists, claiming that adaptive perfectionists strive to achievable goals that are useful to society; whereas maladaptive perfectionists set goals that are difficult and unrealistic to achieve and they are motivated only by their own success.

\footnotetext{
${ }^{1}$ Correspodence to:

Vesna Ćorluka Čerkez, Teaching faculty, University „Džemal Bijedić“ of Mostar

Sv. Leopolda Mandića 10, Mostar, $\mathrm{BiH}$

Phone: +38763990181

E-mail: Vesna.Corluka@unmo.ba
} 
Numerous theoreticians claimed that perfectionism only has negative consequences, among which they emphasized cognitive factors, irrational beliefs and dysfunctional attitudes (Ellis, 1958; Beck, 1979; Burns, 1980, according to Ellis, 2002). In general, the adaptability of perfectionism is defined in relation to its negative consequences, such as depression, anxiety, or low level of self-esteem (Hewitt et al., 2002; McCreary, Joiner, Schmidt \& Ialonga, 2004). However, there are data that show its positive relation to measures of psychological adjustment, e.g. self-esteem (Accordino, Accordino \& Slaney, 2000; Ashby \& Rice, 2002; Molnar, 2006), indicating that perfectionism can be useful in the process of person's development. Despite that, researchers could not agree about the dimensions of perfectionismthe adaptive ones and the ones that are not adaptive.

Most of the earlier researches on the relation of perfectionism and anxiety (Frost, Heimberg, Holt, Mattia \& Neuberg, 1993; Juster et al., 1996; Lauri Korajlija, 2004; Lauri Korajlija 2010), applied general measures of anxiety which was observed as a state and/or personality feature and based on that it was not clear to which aspects of anxiety (test, separation, social etc.) is the perfectionism related, in what measure is this relation visible and which dimensions of perfectionism, mostly individually, contribute to the explanation of these aspects. Also, there have been only few researches on the relation between perfectionism and anxiety on the pattern of children and adolescents. For the purpose of better understanding of the dimensions of perfectionism and their nature, based on their relation to anxiety, in this work we will observe their different manifestations.

This work will use cognitive theoretical frame, and in the frames of cognitive models general constructs, such as perfectionism, is seen as a cognitive style or mental pattern that determines perception, interpretation, experiences and person's behaviour (Lauri Korajlija, 2010). The possibility of changing mental patterns is very significant, because it also changes experience and behaviour.

Developmental perspective in psycho-pathological studies indicates that disorders develop graduallyfrom symptoms, over syndromes, to a disorder (VulićPrtorić, 2001). For the purpose of recognizing children and adolescents that represent risk categories for the development of a certain disorder, it seems significant to research all the levels of anxiety as a psycho-pathological phenomenon and to collect data that can be used preventively, which is one of the goals of this work.

In short, this work aims to answer two research questions: (1) which of the researched dimensions of adap- tive and maladaptive perfectionism are mostly related to different aspects of anxiety; (2) in which measure the variances of anxiety dimensions explain the researched dimensions of perfectionism (sensitivity to mistakes, contingent self-esteem, organisation and order, a need for admiration, perfectionism which is self-oriented and socially prescribed perfectionism).By answering these questions we will also evaluate the classification of the dimensions of perfectionism to adaptive and maladaptive dimensions.

\section{METHOD}

\section{Participants}

200 students participated in the research. It is a group of 104 female (50.5\%) and 102 male students (49.5\%), based on what we can conclude that the pattern is almost completely balanced by the gender. The average age of the participants is $14(\mathrm{SD}=0.98)$, and age range is from 13 to 15.Questionnaires, in which students gave meaningless answers and to which they approached irresponsibly, were excluded from the statistical analysis of the results.

\section{Instruments}

\section{Questionnaire on socio-demographic features}

Socio-demographic variables, which were considered, are: gender and age of the participants, success in school, birth order, self-perception as a student, selfsatisfaction as a student, satisfaction of parents and teachers with the students and how students feel in their class surrounding (if they have many friends, etc.).

\section{Adaptive/maladaptive perfectionism scale (AMPS)}

This scale was formed by Rice \& Preusser (2002) based on the cognitive and psychodynamic understanding of perfectionism and it is consisted of 27 particles or statements that involve four dimensions of perfectionism. First dimension- Sensitivity to mistakes (STM) is consisted of 9 statements that evaluate child's fear and other unpleasant emotions related to mistakes. Second dimension- Contingent self-esteem (CSE), evaluates pleasant emotions related to success and setting of high standards and it consists of 8 statements. Third dimension of perfectionism is Organisation and order (OAO) - it consists of six statements that refer to the need for tidiness and organisation. Last dimension is a Need for admiration (NFA), which consists of four statements that evaluate need or aspiration of a child to be admired and to be given credits for success and effort. 
For the purpose of this research there has been a slight modification before the application. The Likert type scale of four degrees (forced choice scale) was modified to five degrees $(1=$ it doesn't refer to me at all; $3=$ it does and it doesn't refer to me; $5=$ it refers to me completely). According to our opinion, it is fair to offer the participants the option of neutral attitude when it comes to certain statements, since this is not a „delicate matter"where most of the participants would choose neutral answers. The fore mentioned modification also increases the discriminative character of the instrument. A sum of statements is applied as a linear combination and the final result is determined by summarizing the evaluations of the participants. Statements 4, 5, 7, 12, 16 and 17 are scored in an opposite direction. Alfa indices range from.65 for the subscale Contingent self-esteem to .78 for the subscale Need for admiration. Reliability of the entire scale is $\dot{\alpha}=.76$.

\section{Children and adolescents perfectionism scale} (CAPS)

Children and adolescents perfectionism scale (Flett, Hewitt, Boucher, Davidson \& Munro, 2000) is designed for measurement two dimensions of perfectionism among the participants of age 10 to 15 and it is consisted of 22 particles or statements. First dimension is Self-oriented perfectionism (SOP) it consists of 12 statements; the other is Socially prescribed perfectionism (SPP) - it consists of 10 statements. Itis intended for measurement of the source of perfectionism. The participants respond to the statementsby marking their answers on a scale of five degrees in a way that they evaluate in what measure does the certain statement refers to them $(1=$ it doesn't refer to me at all, $5=$ it refers to me totally).A sum of statements is applied as a linear combination and the total result is determined by summarizing the evaluations of the participants. Statements 3, 8 and 9 are pointed in an opposite direction. Cronbach's inner method reliability coefficient for the subscale Self-oriented perfectionism is alpha .78, and for the scale Socially prescribed perfectionism it is alpha $=.83$. Reliability of the entire scale is $\dot{\alpha}=.86$.

Fears and anxiety scale for children and adolescents (SCAD-62)

This scale was formed by the author Vulić-Prtorić (2004) in a way that the symptoms implied by certain statements match the results of empiric and clinical researches. This scale is consisted of 62 particles that include eight subscales of different fears, symptoms and manifestations of anxiety during childhood and adolescence. Seven of them have been applied in our research: test anxiety (TA), separation anxiety (SA), social anxiety (SOCA), anxious panic attacks /agoraphobia attacks (APA), obsessive-compulsive symptoms (OCS), worry (WOR) and somatization (SOM). Participants mark their answers on a Likert scale of five degrees (from $1=$ it's not true at all, to $5=$ it's totally true).A sum of statements is applied as a linear combination and the total result is determined by summarizing the evaluations of the participants. Reliability of the entire scale is $\dot{\alpha}=.95$.

\section{Children and adolescents perfectionism scale (CAPS)}

Children and adolescents perfectionism scale (Flett, Hewitt, Boucher, Davidson \& Munro, 2000) is designed for measurement two dimensions of perfectionism among the participants of age 10 to 15 and it is consisted of 22 particles or statements. First dimension is Self-oriented perfectionism (SOP) it consists of 12 statements; the other is Socially prescribed perfectionism (SPP) - it consists of 10 statements. Itis intended for measurement of the source of perfectionism. The participants respond to the statementsby marking their answers on a scale of five degrees in a way that they evaluate in what measure does the certain statement refers to them $(1=$ it doesn't refer to me at all, $5=$ it refers to me totally).A sum of statements is applied as a linear combination and the total result is determined by summarizing the evaluations of the participants. Statements 3, 8 and 9 are pointed in an opposite direction. Cronbach's inner method reliability coefficient for the subscale Self-oriented perfectionism is alpha .78, and for the scale Socially prescribed perfectionism it is alpha $=.83$. Reliability of the entire scale is $\dot{\alpha}=.86$.

Fears and anxiety scale for children and adolescents (SCAD-62)

This scale was formed by the author Vulić-Prtorić (2004) in a way that the symptoms implied by certain statements match the results of empiric and clinical researches. This scale is consisted of 62 particles that include eight subscales of different fears, symptoms and manifestations of anxiety during childhood and adolescence. 
Seven of them have been applied in our research: test anxiety (TA), separation anxiety (SA), social anxiety (SOCA), anxious panic attacks /agoraphobia attacks (APA), obsessive-compulsive symptoms (OCS), worry (WOR) and somatization (SOM). Participants mark their answers on a Likert scale of five degrees (from $1=$ it's not true at all, to $5=$ it's totally true).A sum of statements is applied as a linear combination and the total result is determined by summarizing the evaluations of the participants. Reliability of the entire scale is $\dot{\alpha}=.95$.

\section{Procedure}

This research has been conducted with the approval of the Ministry of education, science, culture and sports of Herzegovina-Neretva Canton and school principals and also with the accordance of the class teachers in certain classes anòd the agreement of parents. Nine of the eighth grades from two elementary schools in Mostar participated in this research. Tests were applied within 90 minutes (with a short break between two school lessons). The order of the questionnaires was altered between classes in order to avoid sequence effect.

\section{RESULTS}

First step while processing the results was to calculate basic descriptive values on the whole pattern, for all of the research variables and to check the distribution normalities. The results are shown in the following Table.

Table 1. Arithmetic mean, standard deviations and significance of the K-S test

\begin{tabular}{llllll}
\hline Variable & $\mathrm{N}$ & $\mathrm{M}$ & $\mathrm{SD}$ & $\mathrm{K}-\mathrm{S} \mathrm{z}$ & $\mathrm{K}-\mathrm{S} \mathrm{p}$ \\
\hline STM & 200 & 24.83 & 6.90 & .82 & .51 \\
CSE & 200 & 33.17 & 4.85 & 1.39 & $.04 *$ \\
OAO & 200 & 18.31 & 5.90 & 1.23 & .10 \\
NFA & 200 & 12.20 & 4.62 & 1.36 & $.05 *$ \\
SOP & 200 & 36.63 & 9.27 & .92 & .37 \\
SPP & 200 & 27.85 & 8.96 & .91 & .37 \\
TA & 27.02 & 10.53 & 1.02 & .25 \\
SA & 200 & 22.55 & 8.38 & 1.29 & .07 \\
SOCA & 200 & 20.91 & 7.36 & 1.38 & $.05 *$ \\
APA & 200 & 20.00 & 8.14 & 2.34 & $.00 * *$ \\
OCS & 200 & 18.54 & 6.00 & 1.16 & .13 \\
WOR & 200 & 23.67 & 9.47 & 1.14 & .15 \\
SOM & 200 & 28.35 & 10.49 & 1.88 & $.00 * *$ \\
SUM & 200 & 162.31 & 50.72 & .93 & .35 \\
\hline
\end{tabular}

Legend: STM - Sensitivity to mistakes; CSE - Contingent self-esteem; OAO- Organisation and order; NFA - Need for admiration; SOP - Self-oriented perfectionism; SPP - Socially prescribed perfectionism; TA - Test anxiety; SA - Separation anxiety;SOCA Social anxiety; APA - Anxiety sensitivity/panic attacks/agoraphobia; OCS-Obsessive-compulsive symptoms; WOR- Worry; SOM - Somatization; SUM - Sum, total result on the scale SCAD-62;** $\mathrm{p}<.01 ; * \mathrm{p}<.05$.

As it is observable from the Table 1, certain variables (CSE, NFA, SOCA, APA and SOM) significantly deviate from the normality curve. However, during the analysis of the normality and suitability of the variables for the parametric statistics, we have noticed that certain variables also significantly deviate from the normality according to KolmogorovSmirnov z-values, whereas their indices of skewness and kurtosisare within the acceptable limits (from-1 to +1$)$. 
Since the sensitivity of $\mathrm{z}$ - term increases in the function of the results number, we gave priority to the values of skewness and kurtosis indices. For example, the SOCA variable has significantly deviated from the normality at the level of 5\% according to Kolmogorov-Smirnov z-statistics, whereas the skewness and kurtosis indices are within the limits of acceptable values( .56 and -.24). Due to that, we haven't done any transformations, we just included the original variable into parametric analyses. Generally, Tabachnick \& Fidell (2001) suggest avoidance of the normalization of variables, apropos, of doing transformations, because of the difficulties when interpreting the relation between variables.
Authors Aron \& Aron (1994) emphasize that only in cases of extreme deviation of the distribution from the normality, parametric statistics give unacceptable results, which is not the case in our research. Distributions of all the alleged variables are positively asymmetric, what is partly expected, due to the fact that we didn't do the research on the clinical pattern of the participants. Also, the fact that the distribution of the APA results is positively asymmetric and in accordance with the SCAD-62 scale (VulićPrtorić, 2007), shows that a small proportion of children and adolescents experience different kinds of fears related to physical disturbances and agoraphobic situations.

Table 2. Matrix of inter-correlations between adaptive dimensions of perfectionism and certain anxiety subscales

\begin{tabular}{|c|c|c|c|c|c|c|c|c|c|c|}
\hline Subscale & 1. & 2. & 3. & 4. & 5. & 6. & 7. & 8. & 9. & 10. \\
\hline 1. SOP & - & .13 & $.51 * *$ & $.18^{* *}$ & $.23 * *$ & $.23 * *$ & $0.29 * *$ & $.34 * *$ & $.33 * *$ & $.23 * *$ \\
\hline 2. CSE & & - & .07 & .00 & .04 & -.08 & -.09 & -.01 & -.05 & -.05 \\
\hline 3. OAO & & & - & $.41 * *$ & $.44 * *$ & $.34 * *$ & $.40 * *$ & $.50 * *$ & $.51 * *$ & $.44 * *$ \\
\hline 4. TA & & & & - & $.55^{* *}$ & $.68^{* *}$ & $.58 * *$ & $.56^{* *}$ & $.72 * *$ & $.80 * *$ \\
\hline 5. SA & & & & & - & $.53 * *$ & $.69 * *$ & $.58^{* *}$ & $.56^{* *}$ & $.69 * *$ \\
\hline 6. SOCA & & & & & & - & $.60 * *$ & $.51 * *$ & $.69 * *$ & $.70 * *$ \\
\hline 7. APA & & & & & & & - & $.63 * *$ & $.62 * *$ & $.89 * *$ \\
\hline 8. OCS & & & & & & & & - & $.61^{* *}$ & $.66^{* *}$ \\
\hline 9. WOR & & & & & & & & & - & $.69 * *$ \\
\hline 10. SOM & & & & & & & & & & - \\
\hline
\end{tabular}

Legend: SOP - Self-oriented perfectionism; CSE-Contingent self-esteem; OAO - Organisation and order; TA - test anxiety; SA - Separation anxiety; SOCA - Social anxiety; APA - Anxiety sensitivity/panic attacks/agoraphobia; OCS- Obsessive-compulsive symptoms; WOR - Worry; SOM - Somatization; ** $\mathrm{p}<.01$.

When it comes to examining the relation between dimensions of perfectionism that turned out to be adaptive in previous researches - SOP, CSE and OAO (Frost et al., 1993; Rice, Ashby \& Slaney, 1998; Dixon, Lapsley \& Hanchon, 2004; Rice, Kubal \& Preusseer, 2004; Lauri Korajlija, 2010) and anxiety we used Pearson's correlation coefficient. From the Table 2 it is observable that the CSE variable of perfectionism doesn't relate significantly to the anxiety variables, confirming the previous data that this is a positive aspect of perfectionism (Lauri Korajlija, 2010; Rice et al., 2004). The other two variables of perfectionism (CSE and OAO) are statistically significantly and positively related to all of the aspects of anxiety at the level less than 1\%. From the Table 2 it is also observable that all inter-correlation coefficients of the anxiety subscales are statistically significant at the level less than $1 \%$, and they range from .51 to .89 . According to Zinbarg \& Barlow (1996), correlation coefficients between anxiety subscales should be less than .60, what represents a level of meaningful differentiation between certain dimensions. However, high or very high corelation (from .55 to .91 ) betweensubscales of anxiety indicates the existence of a common factor of higher order (Spence, 1997; 1998, according to Vulić-Prtorić, 2007). 
Table 3. Matrix of inter-correlation between maladaptive dimensions of perfectionism and certain anxiety subscales

\begin{tabular}{|c|c|c|c|c|c|c|c|c|c|c|}
\hline Subscale & 1. & 2. & 3. & 4. & 5. & 6. & 7. & 8. & 9. & 10. \\
\hline 1. SPP & - & $.24 * *$ & $.50 * *$ & $.21 * *$ & $.20 * *$ & $.26^{* *}$ & $.29 * *$ & $.34 * *$ & $.31 * *$ & $.26 * *$ \\
\hline 2. STM & & - & $.33 * *$ & $.43 * *$ & $.42 * *$ & $.39 * *$ & $.39 * *$ & $.49 * *$ & $.54 * *$ & $.44 * *$ \\
\hline 3. NFA & & & - & $.35 * *$ & $.35 * *$ & $.36^{* *}$ & $.36 * *$ & $.39 * *$ & $.45^{* *}$ & $.36 * *$ \\
\hline 4. TA & & & & - & $.55 * *$ & $.68 * *$ & $.58 * *$ & $.56^{* *}$ & $.72 * *$ & $.80 * *$ \\
\hline 5. SA & & & & & - & $.53 * *$ & $.69 * *$ & $.58 * *$ & $.56^{* *}$ & $.69 * *$ \\
\hline 6. SOCA & & & & & & - & $.60 * *$ & $.51 * *$ & $.69 * *$ & $.70 * *$ \\
\hline 7. APA & & & & & & & - & $.63 * *$ & $.62 * *$ & $.89 * *$ \\
\hline 8. OCS & & & & & & & & - & $.61 * *$ & $.66^{* *}$ \\
\hline 9. WOR & & & & & & & & & - & $.69 * *$ \\
\hline 10. SOM & & & & & & & & & & - \\
\hline
\end{tabular}

Legend: SOP - Socially prescribed perfectionism; STM - sensitivity to mistakes; NFA - Need for admiration; TA - test anxiety; SA - Separation anxiety; SOCA - Social anxiety; APA - Anxiety sensitivity/panic attacks/agoraphobia; OCS - Obsessive-compulsive symptoms; WOR - Worry; SOM - Somatization; ** $\mathrm{p}<.01$.

When it comes to examining the relation between dimensions of perfectionism that turned out to be maladaptive in the previous researches - SPP, STM and NFA (Accordino et al., 2000; Flett \& Hewitt, 2002; Gilman \& Ashby, 2003; Dixon et al., 2004; Chang, Watkins \& Banks, 2004; Rice e al., 2004) and anxiety, we have used the Pearson's correlation coefficient. From the Table 3 it is observable that all three dimensions of perfectionism (SPP, STM and NFA) have moderate (to medium), but statistically significant and positive correlations with all of the anxiety subscales, as expected. Dimension SPP has the highest correlation with the subscale OCS $(\mathrm{r}=.34, \mathrm{p}<.01)$, whereas the dimensions of perfectionism STM and NFA have the highest correlations with the subscale WOR ( $\mathrm{r}=$ $.54, \mathrm{p}<.01$ and $\mathrm{r}=.45, \mathrm{p}<.01)$.

With the purpose of determining the contribution of the perfectionism variables to the explanation of anxiety and depression, standard multiple regression analyses have been applied.

Table 4. Standard multiple regression analysis of Test and Separation anxiety.

\begin{tabular}{|c|c|c|c|c|c|c|}
\hline & \multicolumn{3}{|l|}{ TEST } & \multicolumn{3}{|c|}{ SEPARATION } \\
\hline & $\mathrm{R}$ & $\beta$ & $\mathrm{sr}^{2}$ & $\mathrm{r}$ & $\beta$ & $\mathrm{sr}^{2}$ \\
\hline STM & $.43 * *$ & $.37 * *$ & .30 & $.42 * *$ & $.33 * *$ & .26 \\
\hline CSE & .00 & .06 & .06 & .04 & .08 & .08 \\
\hline OAO & $.41 * *$ & $.22 * *$ & .17 & $.44 * *$ & $.25^{* *}$ & .19 \\
\hline NFA & $.35^{* *}$ & $.23 * *$ & .17 & $.35^{* *}$ & $.19^{*}$ & .14 \\
\hline SOP & $.18 * *$ & $-.29 * *$ & -.21 & $.23 * *$ & $-.20 *$ & -.14 \\
\hline \multirow[t]{6}{*}{ SPP } & $.21 * *$ & .09 & .07 & $.20 * *$ & .05 & .04 \\
\hline & & $\sum \mathrm{sr}^{2} 3=$ & .56 & & $\sum \mathrm{sr}^{2} 4=$ & .57 \\
\hline & $\mathrm{R}$ & .54 & & & .53 & \\
\hline & $\mathrm{R}^{2}$ & .30 & & & .28 & \\
\hline & $\mathrm{CR}^{2}$ & .27 & & & .26 & \\
\hline & $\mathrm{F}$ & $13.91 * *$ & & & $12.87 * *$ & \\
\hline
\end{tabular}

Legend: STM - Sensitivity to mistakes; CSE - Contingent self-esteem; OAO - Organisation and order; NFA - Need for admiration; SOP - Self-oriented perfectionism; SPP - Socially prescribed perfectionism; ** $\mathrm{p}<.01 ; * \mathrm{p}<.05$. 
Standard beta-coefficients represent a measure of contribution of certain variables, apropos, predictors, to the model. Higher $\beta$ value indicates that the unit of change in a certain predictor variable has a greater effect on the criterion variable. Similar to that, the higher the $\mathrm{t}$-value is and the lesser the $\mathrm{p}$-value is, it is greater the effect of the predictor variable on the criterion variable of the research (Brace, Kemp \& Snelgar, 2006).

From the Table 4 it is observable that the following dimensions of perfectionism contribute to the explanation of the test anxiety: STM $(\beta=.37, \mathrm{p}<.01)$, SOP $(\beta=-.29, \mathrm{p}<.01), \mathrm{NFA}(\beta=.23, \mathrm{p}<.01)$ and $\mathrm{OAO}(\beta=$ $.22, \mathrm{p}<.01)$. Students that are more anxious in differ- ent test situation are more sensitive to mistakes and have a more prominent need for admiration, organisation and order. Self-oriented perfectionism (SOP) appears as a second most significant predictor for the explanation of anxiety- its individual contribution is $29 \%$ and it is negative. Following dimensions contribute to the explanation of separation anxiety the most: STM $(\beta=.33, p<.01)$, OAO $(\beta=.25, p<.01)$, $\operatorname{SPP}(\beta=-.20, \mathrm{p}<.05)$ and NFA $(\beta=.19, \mathrm{p}<.05)$. Also, the need for admiration (NFA) turned out to be significant for the explanation of separation anxiety $(14 \%$ of the individual contribution), on a level lesser than $5 \%$, whereas for the test anxiety it is significant on a level lesser than $1 \%$.

Table 5. Standard multiple regression analysis of Social anxiety and APA

\begin{tabular}{|c|c|c|c|c|c|c|}
\hline & SOCIA & & & APA & & \\
\hline & $\mathrm{r}$ & $\beta$ & $\mathrm{sr}^{2}$ & $r$ & $\beta$ & $\mathrm{sr}^{2}$ \\
\hline STM & $.39 * *$ & $.29 * *$ & .23 & $.39 * *$ & $.23 * *$ & .19 \\
\hline CSE & -.08 & -.06 & -.05 & -.09 & -.06 & -.06 \\
\hline $\mathrm{OAO}$ & $.34 * *$ & .12 & .09 & $.40 * *$ & .16 & .12 \\
\hline NFA & $.36 * *$ & $.24 * *$ & .18 & $.36 * *$ & $.17 *$ & .13 \\
\hline SOP & $.23 * *$ & -.15 & -.11 & $.29 * *$ & -.07 & -.05 \\
\hline SPP & $.26^{* *}$ & .10 & .08 & $.29 * *$ & .10 & .08 \\
\hline & & $\sum \operatorname{sr}^{2} 5=$ & .42 & & $\sum \operatorname{sr}^{2} 6=$ & .41 \\
\hline & $\mathrm{R}$ & .49 & & & .46 & \\
\hline & $\mathrm{R}^{2}$ & .24 & & & .21 & \\
\hline & $\mathrm{CR}^{2}$ & .22 & & & .19 & \\
\hline & $\mathrm{F}$ & $10.42 * *$ & & & $8.97 * *$ & \\
\hline
\end{tabular}

Legend: STM - Sensitivity to mistakes; CSE - Contingent self-esteem; OAO- Organisation and order; NFA - Need for admiration; SOP-Self-oriented perfectionism; SPP - Socially prescribedperfectionism; APA - Anxiety sensitivity/panic attacks/agoraphobia; $* * \mathrm{p}<.01 ; * \mathrm{p}<.05$.

Following dimension contribute the most to the explanation of social anxiety: STM $(\beta=.29, \mathrm{p}<.01)$ and NFA $(\beta=.24, p<.01)-($ see Table 5$)$. Dimensions OAO $(\mathrm{r}=.34, \mathrm{p}<.01)$, SOP $(\mathrm{r}=.23, \mathrm{p}<.01)$ and SPP $(\mathrm{r}=.26, \mathrm{p}<.01)$ have a positive relation to social anxiety, however, they didn't turn out to be significant predictors for the explanation of this criterion variable. For the explanation of second criterion variable from the Table 5-Anxiety sensitivity/panic attacks/agoraphobia (APA), STM $(\beta=.23, p<.01)$ and NFA $(\beta=$ $.17, \mathrm{p}<.05)$ are the most prominent dimensions. As it is the case with social anxiety, dimension OAO (r= $.40, \mathrm{p}<.01)$, SOP $(r=.29, \mathrm{p}<.01)$ and $\operatorname{SPP}(r=.29, \mathrm{p}<$ .01 ) are positively related to the APA, however, they didn't turn out to be significant predictors for the explanation of this variable. 
Table 6. Standard multiple regression analysis of OCS and Worry

\begin{tabular}{|c|c|c|c|c|c|c|}
\hline & \multicolumn{3}{|l|}{ OCS } & \multicolumn{3}{|c|}{ WORRY } \\
\hline & $\mathrm{r}$ & $\beta$ & $\mathrm{sr}^{2}$ & $\mathrm{r}$ & $\beta$ & $\mathrm{sr}^{2}$ \\
\hline STM & $.49 * *$ & $.30 * *$ & .24 & $.54 * *$ & $.40 * *$ & .32 \\
\hline CSE & .01 & .05 & .05 & -.05 & -.01 & -.01 \\
\hline $\mathrm{OAO}$ & $.50 * *$ & $.27 * *$ & .20 & $.51 * *$ & $.23 * *$ & .18 \\
\hline NFA & $.39 * *$ & .10 & .07 & $.45 * *$ & $.24 * *$ & .18 \\
\hline SOP & $.34 * *$ & -.11 & -.08 & $.33 * *$ & $-.17 *$ & -.12 \\
\hline \multirow[t]{6}{*}{ SPP } & $.34 * *$ & $.19^{* *}$ & .15 & $.31 * *$ & .10 & .08 \\
\hline & & $\sum \mathrm{sr}^{2} 7=$ & .63 & & $\sum \mathrm{sr}^{2} 8=$ & .63 \\
\hline & $\mathrm{R}$ & .57 & & & .65 & \\
\hline & $\mathrm{R}^{2}$ & .33 & & & .42 & \\
\hline & $\mathrm{CR}^{2}$ & .31 & & & .40 & \\
\hline & $\mathrm{F}$ & $16.22 * *$ & & & $23.80 * *$ & \\
\hline
\end{tabular}

Legend: STM - Sensitivity to mistakes; CSE - Contingent self-esteem; OAO - Organisation and order; NFA - Need for admiration; SOP - Self-oriented perfectionism; SPP - Socially prescribed perfectionism; OCS- Obsessive-compulsive symptoms; ** $\mathrm{p}<$ $.01 ; * \mathrm{p}<.05$.

Variables OAO and SPP have a significant individual contribution to the explanation of criterion variable OCS (Table 6). For the prediction worry significant predictors are STM $(\beta=.40, p<.01)$, NFA $(\beta=.24$, $\mathrm{p}<.01)$, OAO $(\beta=.23, \mathrm{p}<.01)$ and SOP $(\beta=-.17$, $\mathrm{p}<.05)$. Dimension SPP is positively related to this criterion variable $(\mathrm{r}=.31, \mathrm{p}<.01)$, but it didn't turn out to be significant predictor for the explanation of Worry (WOR). The participants who worry more are also more sensitive to mistakes and have a more prominent need for admiration and organisation and order.

Table 7. Standard multiple regression analysis of criterion variable somatization

\begin{tabular}{llll}
\hline & \multicolumn{2}{l}{ SOMATIZATION } & \\
\cline { 2 - 4 } STM & $\mathrm{r}$ & \multicolumn{2}{l}{$\mathrm{sr}^{2}$} \\
\cline { 2 - 4 } CSE & $.44^{* *}$ & $.32^{* *}$ & .25 \\
OAO & -.05 & -.01 & -.01 \\
$\mathrm{NFA}$ & $.44^{* *}$ & $.25^{* *}$ & .19 \\
$\mathrm{SOP}$ & $.36^{* *}$ & $.19^{*}$ & .14 \\
$\mathrm{SPP}$ & $.23^{* *}$ & $-.22^{* *}$ & -.15 \\
& $.26^{* *}$ & .12 & .10 \\
& & $\sum \mathrm{sr}^{2} 7=$ & .52 \\
& $\mathrm{R}$ & .55 & \\
& $\mathrm{R}^{2}$ & .30 & \\
& $\mathrm{CR}$ & .28 & \\
& $\mathrm{~F}$ & $14.18^{* *}$ & \\
\hline
\end{tabular}

Legend: STM - Sensitivity to mistakes; CSE - Contingent self-esteem; OAO - Organisation and order; NFA - Need for admiration; $\mathrm{SOP}$ - Self-oriented perfectionism; SPP - Socially prescribed perfectionism; $* * \mathrm{p}<.01 ; * \mathrm{p}<.05$. 
The most significant contribution to the explanation of somatization (Table 7) have the following dimensions: $\operatorname{STM}(\beta=.32, \mathrm{p}<.01)$, OAO $(\beta=.25, \mathrm{p}<.01), \operatorname{SOP}(\beta=$ $-.22, \mathrm{p}<.01)$ and NFA $(\beta=.19, \mathrm{p}<.05)$. As it is the case with the prediction worry, the dimension of perfectionism SPP is positively related to Somatization $(r=0,26$, $\mathrm{p}<0,01$ ), but it didn't turn out to be a significant predictor for its explanation.

\section{DISCUSSION}

This study contributes to our knowledge about anxiety among the younger adolescents by researching the role of perfectionism dimensions in the explanation of its different aspects.

Socially prescribed perfectionism is most closely related to the subscale of obsessive-compulsive symptoms, whereas the perfectionism dimensions sensitivity to mistakes and need for admiration have the highest correlation with the subscale of worry. According to the given results, it can be concluded that participants who have higher results on the subscale socially prescribed perfectionism also have a more prominent need for control and suppression of their feelings. So children and adolescents with high results on the scale of obsessive-compulsive symptoms waste much energy and time on reducing the tension caused by thoughts and actions that are imposed on them (Vulić-Prtorić, 2007). Nevertheless, the same author emphasizes that when evaluating obsessive-compulsive symptoms we need to differ between developmentally appropriate behaviour and concern and rituals and obsessive thoughts that are symptoms of disorder and present a serious problem in child's everyday life.

Similarly, participants that have higher results on the subscale sensitivity to mistakes are at the same time more worried because of the possibility of making mistake and losing control.

Likewise, with the case of sensitivity to mistakes, participants who have more prominent need for getting credits for their effort and success in fact worry about the possible negative outcome, they feel insecurity in situations of social evaluation.

Students who are more anxious in different test situations are more sensitive to mistakes and have a more prominent need for admiration, organisation and order. According to the authors (Rice\& Preusser, 2002), in certain cases, children who have very prominent need for organisation and order are trying to avoid mistakes or to receive positive reactions from others, or both.
In these cases, authors see an excessive need for organisation and order similar to the obsessive-compulsive ways of approaching, reflecting the prospects on maladaptive nature of this dimension. Students who feel discomfort and insecurity when separating from parents and safety of their home, followed by physical symptoms such as nausea and rapid heartbeat, are also more sensitive to mistakes, due to what they try to regain control and avoid possible danger with compulsiveness, apropos with organisation and order.

Results indicate that sensitivity to mistakes and need for admiration mostly contribute to the explanation of social anxiety. Socially anxious participants are very sensitive to mistakes and have a prominent need for social approval. Similar to this, participants who have a more prominent fear of developing anxious and physical reactions related to anxiety and who tend to have panic attacks (short-lasting period of sudden intensive fear or horror) and who fear of the same (main component of agoraphobia) - (Vulić-Prtorić, 2007), accept less than ,perfect"very hard and they have a prominent need for getting credits for their effort. These results are in accordance with the results of the research on prominence of the perfectionism among persons with anxious disorders (panic disorder and social phobia or specific phobias) and persons from comparative group (Antony, Purdon, Huta\& Swinson, 1998). This research has shown that persons with social phobia and panic disorder have a more prominent doubt about their acts and fear of mistakes in relation to healthy persons. Only the persons with specific phobias did not differ from the healthy persons. It is important to bear in mind that in order to set the diagnosis of social phobia, symptoms of social anxiety have to significantly disturb everyday life and last for at least six months. Temporarily anxieties are very common during childhood and adolescence, e.g. an adolescent refuses to eat in a school cantina for a while, but later starts behaving in a usual way again (Vulić-Prtorić, 2007). According to the same author, when evaluating the symptoms of anxiety sensitivity/panic attacks/agoraphobia (APA) among children and adolescents, a special attention has to be paid to the child's health status, due to the fact that different physical diseases can cause reactions similar to those described in the APA scale. It is also important to differ between perfectionism behaviours and rituals in different developmental stages of children's lives from the rituals and thoughts that represent symptoms of disorders and make everyday life difficult (e.g. child is excessively preoccupied with time). 
It has been shown that participants who have prominent somatization are more sensitive to mistakes and have a more prominent need for organisation and order and getting credits for their effort. Previous researches did not question the contribution of the perfectionism dimensions to the explanation of this anxiety variable, but we can say that our result is in accordance with the expected, especially when it comes to sensitivity to mistakes.

\section{CONCLUSIONS}

Generally, when defining the criteria measures of anxiety, all of the predictor measures for which we assumed to be maladaptive play a significant role, along with the dimension organisation and order that turned out to be adaptive in the previous researches. Sensitivity to mistakes is a dimension of perfectionism that has the most significant contribution to the explanation of anxiety and it turned out to be significant in the prediction of all seven anxiety variables. Socially prescribed perfectionism stands out as a significant predictor only in explanation of the obsessive-compulsive symptoms.Generally, we can conclude that perfectionism is at least one of the psychological factors that explains somatization. Symptoms that occur in this cases involve pains in different parts of the body (head, back, joints etc.), gastrointestinal symptoms like nausea and vomiting, sexual issues like irregular periods and psycho-neurological symptoms (Vulić-Prtorić, 2007).Despite of the positive relation to the anxiety measures, self-oriented perfectionism is significant, but negative predictor, in certain criteria measures of anxiety, supporting the opinions on adaptive nature of this measure.

\section{Declaration of Conflicting Interests}

The author declared no potential conflicts of interest with respect to the authorship and/or publication of this article.

\section{Funding}

The author received no financial support for the research and/or authorship of this article.

\section{REFERENCES}

Accordino, D. B., Accordino, M. P., \& Slaney, R. B. (2000). An investigation of perfectionism, mental health, achievement, and achievement motivation in adolescents. Psychology in the Schools, 37(6), 535-545.
Antony, M. M., Purdon, C. L., Huta, V., \& Swinson, R. P. (1998). Dimensions of perfectionism across anxiety disorders. Cognitive Therapy and Research, 36, 1143-1154.

Aron, A., \& Aron, E. N. (1994). Statistics for psychology. Englewood Cliffs, NJ: Prentice-Hall.

Ashby, J. S.,\& Rice, K. G. (2002). Perfectionism, dysfunctional attitudes, and self-esteem: A structural equations analysis. Journal of Counseling and Development, 80, 197-203.

Brace, N., Kemp, R., \& Snelgar, R. (2006). SPSS For Psychologists: A Guide To Data Analysis Using SPSS For Windows (3rd ed.). Mahwah, NJ: Lawrence Erlbaum Associates.

Chang, E. C., Watkins, A. F., \& Banks, K. H. (2004). How adaptive and maladaptive perfectionism relate to positive and negative psychological functioning: Testing a stressmediation model in Black and White college students. Journal of Counseling Psychology, 51 (1), 93-102.

Dixon, F. A., Lapsley, D. K., \& Hanchon, T. A. (2004). An empirical typology of perfectionism in gifted adolescents. Gifted child quarterly, 48, 95-106

Ellis, A. (2002). The role of irrational beliefs in perfectionism. In G. L. Flett i P. L. Hewitt (Eds.), Perfectionism: Theory, Research and Treatment. Washington DC: American Psychological Association.

Flett, G.L., \& Hewitt, P.L. (2002). Perfectionism. Theory, Research and Treatment. Washington, DC: American Psychological Association.

Flett, G.L., Hewitt, P.L., Boucher, D.J., Davidson, L.A., \& Munro, Y. (2000). The Child-Adolescent Perfectionism Scale: Development, validation, and association with adjustment. Unpublished manuscript

Frost, R. O., Heimberg, R. G., Holt, C. S., Mattia, J. I., \& Neubauer, A. L. (1993). AComparasion of two measures of perfectionism. Personality and Individual Differences, 14 (1), 119-126.

Gilman, R., \& Ashby, J. S. (2003). Multidimensional perfectionism in a sample of middle school students: An exploratory investigation. Psychology in the School, 40(6), 677689.

Hadžić, A. (2011). Perfekcionizam i psihološka dobrobit (Neobjavljeni završni diplomski rad). Filozofski fakultet, Sarajevo.

Hewitt, P. L., Caelian, C. F., Flett, G. L., Sherry, S. B., Collins, L., \& Flynn, C. A. (2002). Perfectionism in children: associations with depression, anxiety, and anger. Personality and Individual Differences, 32(6), 1049-1061.

Juster, H. R., Heimberg, R. G., Frost, R. O., Holt, C. S., Mattia, J. I., \& Faccenda, K. (1996).Social Phobia and Perfectionism. Personality and Individual Differences, 21(3), 403-410.

Lauri Korajlija, A. (2004). Povezanost perfekcionizma i atribucijskog stila s depresivnošću $i$ anksioznošću. Neobjavljeni magistarski rad. Zagreb: Odsjek za psihologiju Filozofskog fakulteta u Zagrebu.

Lauri Korajlija, A. (2010). Perfekcionizam i anksiozna osjetljivost kao rizični faktori za pojavu anksioznih smetnji: kvantitativna i kvalitativna studija. Neobjavljena doktorska disertacija. Zagreb: Odsjek za psihologiju Filozofskog fakulteta u Zagrebu. 
McCreary, B. T., Joiner, T. E., Schmidt, N. B., \& Ialango, N. S. (2004). The structure and correlates of perfectionism in African American children. Journal of Clinical Child and Adolescent Psychology, 33(2), 313-324.

Molnar, M. (2006). Povezanost perfekcionizma sa samopoštovanjem $i$ zadovoljstvom kvalitetom života. Neobjavljeni diplomski rad. Zagreb: Odsjek za psihologiju Filozofskog fakulteta u Zagrebu

Rice, K. G., Ashby, J. S., \& Slaney, R. B. (1998). Self-esteem as a mediator between perfectionism and depression: a structural equations analysis. Journal of Counseling Psychology, 45(3), 304-314.

Rice, K. G., Kubal, A. E., \& Preusseer, K. J. (2004). Perfectionism and children's self-concept: Further validation of the Adaptive/Maladaptive Perfectionism Scale. Psychology in the Schools, 41 (3), 279-290.
Rice, K. G., \& Preusser, K. J. (2002). The Adaptive/Maladaptive Perfectionism Scale.Measurement and Evaluation in Counseling and Development, 34, 210-222.

Shafran, R., \& Mansell, W. (2001). Perfectionism and psychopathology: A review of research and treatment. Clinical Psychology Review, 21(6), 879-906.

Tabachnick, B. G., \& Fidell, L. S. (2001). Using Multivariate Statistics (4th ed.). Needham Heights, MA: Allyn and Bacon.

Vulić-Prtorić, A. (2001). Razvojna psihopatologija: "Normalan razvoj koji je krenuo krivim putem." Radovi Filozofskog fakulteta u Zadru, 40(17), 161-186.

Vulić-Prtorić A. (2007). Priručnik za Skalu strahova i anksioznosti za djecu i adolescente SKAD-62. Jastrebarsko: Naklada Slap.

Zinbarg, R., \& Barlow, D.H. (1996). The structure of anxiety and the DSM-III-R anxiety disorders: A hierarchical model. Journal of Abnormal Psychology, 105,181-193. 